\title{
Two Experiences of Blended Learning Process on Engineering Education
}

\author{
http://dx.doi.org/10.3991/ijoe.v12i09.6146 \\ A.A. Rodríguez-Sevillano, M.A. Barcala-Montejano, E. Tovar-Caro, P. López-Gallego \\ Universidad Politécnica de Madrid, Madrid, Spain
}

\begin{abstract}
The paper presents the experience developed by the authors in two virtual learning platforms oriented to learning about helicopters in aerospace engineering. The first course on OCW-UPM project will be explained, and as well as the evolution towards a step further in open education resources with the course "Introduction to Engineering Helicopter" in edX. The results obtained in each course will be analyzed, and the conclusions taken into account.
\end{abstract}

Index Terms-blended learning, edX, engineering education, MOOCs, OCW.

\section{INTRODUCTION}

New learning environments [1] are nowadays an essential complement to the teaching-learning process. They have broken the frontiers of traditional learning, so that the classical scheme of student-teacher can now include comprehensive procedures where students, following a schedule proposed by the teaching staff, make use of learning tools and they organize their time in a way that is known as autonomous learning.

There is a widespread consensus in the teaching community that traditional teaching must be capable of evolving to keep pace with the rapid developments in information technology. New ways of teaching need to be elaborated; these new procedures should maintain the advantages of the traditional teaching-learning process but should also be able to meet the changing demands of society.

Throughout the years, an alternative teaching method such as distance learning had moved from correspondence learning to educational forums with video conferences and teleconferences. The spread of the Internet and the development of new educational software have brought with them a more flexible education way which has been named as virtual education [6].

One step forward in the evolution of virtual education consists of Open Content Resources [3], [5] and, in special, the Open Course Ware project, initiated by the MIT and which has been followed by many universities all over the world. The new concept is based on the idea of making knowledge [4] contents available not only to higher education students but also to any person wishing to expand his/her knowledge on any specific theme or to scholars who would like to be informed of the new approaches to specific matters by other universities.

The paper presents the development of these teaching tools in the module of Helicopters, in the syllabus of the Aeronautics and Aerospace Engineering degree. These resources were developed from the classic slides or illustrated figures, including the virtual animations that are part of the learning tools posted on the OCW- UPM [2] website. This evolution of learning tools, as well as the new idea of autonomous learning, served as a launch pad to design the edX course. The concept of Massive Open Online Courses (MOOCs) [3]-[14] radically changes the perspective of the teacher's role; the teacher addresses an almost unlimited worldwide audience with a heterogeneous knowledge, and the model of student learning is based on planning and resources management with a high level of independence.

The course belongs to Universidad Politécnica de Madrid (Technical University of Madrid). This University promotes the creation of MOOCs from the OCW courses already published. This strategy is fostered by Open Education Consortium (OECx), a worldwide community [16] of hundreds of higher education and associated organizations, joined by Technical University of Madrid. According to this Consortium, all materials used in courses under the OECX banner must be open educational resources [17].

OER (Open Educational Resources) which have been published in the institutional OCW site follow the recommendations studied and according to the strategy of the institution and requirements of $\mathrm{OECx}$.

As with other e-learning courses [18], the terms of admission are clearly defined, with time-line activities, average weekly dedication, task deadlines, and monitoring by the teaching team, with real-time interaction with the students through wikis and blogs.

The article presents statistics for the results, participation, drop-outs, and also recommendations for improvement.

\section{E-LEARNING CONCEPT}

We must keep in mind that e-learning is basically a way to learn based on information technology [19]. Its main purpose is to design student-centered [2] learning objects. It's a means to spread learning materials, not as an end in itself.

Continuing with [19], the author makes an interesting classification based on technological means that have been used, and the result is: CBT (computer based training), IBT (Internet based training), and WBT (web based training). The OCW learning model will be fundamentally focused on the latter.

The concept of e-learning has spread thought the world. As a result, the term e-learning [20] in the strict sense, when it is based solely on distance learning, has intertwined with the concept of blended learning, which as the term itself indicates, is a learning model that uses face-toface learning with remote tools. 
As some of the most important elements according to [21], the student can progress in the course at their own pace of learning by combining the resources depicted in Fig. 1 whenever be needed (just-in-time learning).

\section{THE OCW-UPM HELICOPTERS COURSE}

The OCW-UPM project is part of the open education concept providing open educational resources to educators, students and anybody with an educational interest in a specific area.

This project was started in MIT in 2001, presenting a way to publish free access materials for its courses. Therefore the Open Education Consortium was created (a nongovernmental organization extended worldwide), as a network of educational institutions [9] that aims to accommodate open education through collaboration, innovation and collective development.

The aim is to promote education by sharing resources, tools and practices within a framework of open access. Education serves as a tool of individual and social empowerment, which can cope with present and future challenges, so that the technological revolution of the digital age and the Internet can overcome economic, social and cultural barriers. It's an effective alternative to the right to education according to the Universal Declaration of $\mathrm{Hu}-$ man Rights.

According to the authors of this article, it is interesting to note, among the most important characteristics of autonomous learning based on OCW, the following [22]: learning supported by self-assessment, specifically designed exercises and illustrations as well as proposals for collaborative work.

The OCW-UPM course involves the natural evolution of the teaching Helicopters course in the Aeronautical Engineering degree at Technical University of Madrid (Universidad Politécnica de Madrid). The Helicopters course was based on traditional lectures (which we should never underestimate), however it was necessary to rely on multimedia tools to show clearly some systems and some helicopter flying concepts, due to the complexity involved. The successful use of multimedia and interactive tools, as an additional technique to traditional teaching, was the trigger for the evolution towards the development of the OCW-UPM Helicopters course project.

It should be clarified that the concept of an OCW course is not a platform of tele-education for in-class students. It is, as already mentioned, an open free access course, so that the student plans his time to achieve the proposed learning. Additionally, OCW is a showcase of the materials used in the course to make them available to the general public.

It is interesting to analyze some of the results of the OCW-UPM Helicopters course in relation to the number of users accumulated in these 7 years. To summarize the data, we note that the course is among the most visited in the OCW-UPM, as shown in Fig. 2.

Regarding the evolution of the number of entries during these 8 years, we can highlight a very high impact at the beginning, with remarkable values in November 2008 (763 sessions) to a stable value over the last years, close to 200 sessions in 2013, 2014 and 2015. A summary of this information can be analyzed in detail in Fig. 3.

To complete the analysis of this course, it would also be interesting to know the distribution of visitors at the mo- ment of accessing, whether or not it's their first access (Fig. 4). In addition, it would be interesting to analyze the duration of the visit depending on the type of visitor (new or not) according to Fig. 5. For the teaching staff, it is gratifying to see that after a first visit, the students return to the course and spend more time in their sessions. This means that the materials attract their attention and they find them quite interesting.

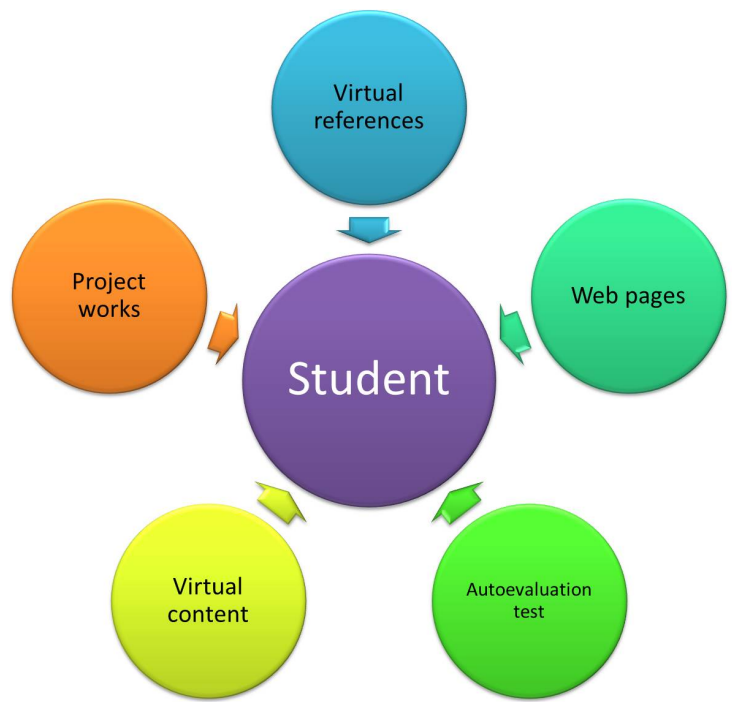

Figure 1. Student centered learning model

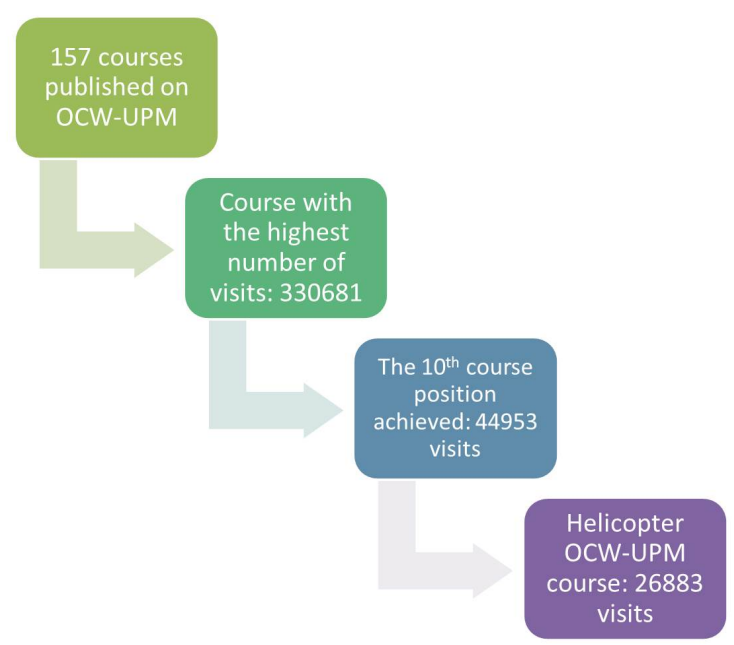

Figure 2. Main figures of OCW-UPM Helicopters course

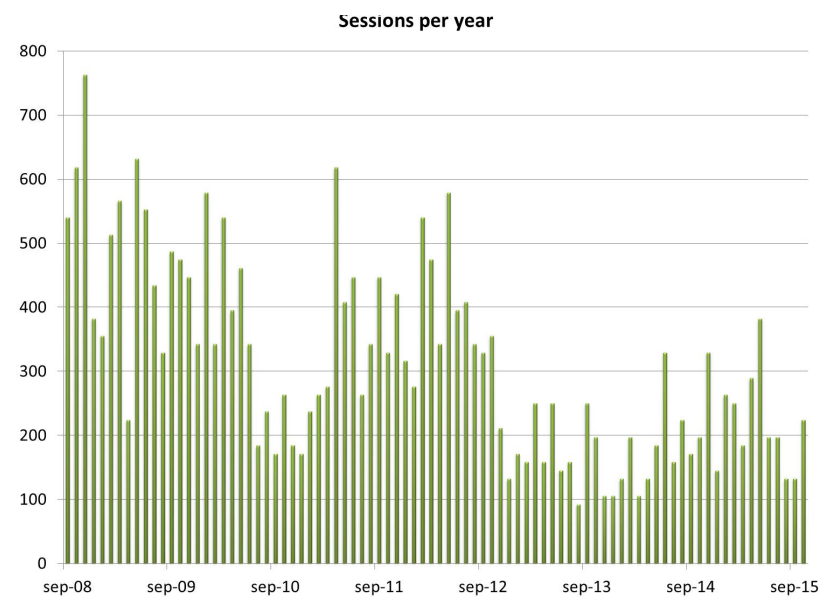

Figure 3. Acumulated data of sessions on a yearly basis 


\section{MASSIVE Open OnLine Courses}

The concept of Massive Open Online Courses (MOOCs) radically changes the perspective of the teacher's role; the teacher addresses an almost unlimited worldwide audience with a heterogeneous knowledge [23], [24] and the model of student learning is based on planning and resources management with a high level of independence.

This appearance of MOOCs [25] can be understood as a complement to classical learning tools in which the teacher provides to the student in line with the technological advances of society. However, it is also something more: it is a foundation of lifelong learning (LLL), a idea introduced in 1971. This concept refers to a self-motivated pursuit of knowledge regardless of the age of the adult.

MOOCs provide alternative ways for students to gain new knowledge according to a given curriculum [26]. But MOOCs awaken more challenges not only for academic staff but also for institutions [27], as new learning methods and assessment [28], and analysis of how to include them in current official studies programs.

Characteristics of a MOOC can differentiate a MOOC from other types of online courses. This is one of the central questions of the debate on the future of MOOCs, along with the learners' attitudes such as attrition or a lack of satisfaction that leads to disengagement or dropout.

We also consider interesting to analyze the electronic device used for web access. These information (Fig. 6) may be a proof of the level of accessibility of the platform. It is mostly used in personal computers. We are sure that it is a trend that will decrease drastically in the coming years.

Even basic characteristics of a MOOC, such as the number of students, or the degree of involvement of the teaching team once a course has started, can blur between courses, some of which are called MOOC and some are not. A study proposes a quality model based on both course structure and certification process [29], although it is difficult to specify a quality model, given the wide range of parameters for different online courses, which may or may not be conceived as being MOOC. The authors proposed a quality model considering the overall structure and function of each course in terms of a variable set of characteristics that could be used to evaluate the initial design of the course, and the use of a flexible student certification model, to demonstrate, as far as it is possible, that a course had achieved its objectives and had achieved the results intended by the teaching team.

Another problem to be considered concerns the effort that needed to be made at the design stage. This effort includes among other things, depending always on the duration of the course, the production of materials, mainly video lectures, that need to be generated, the design of discussions through forums or others social tools, and the design of new assessment exercises and practices to adapt the course to a massive audience.

There are several strategies so as not underestimate the time needed for the preparation of learning materials (particularly video lectures), or for their upload to the platform. Examples of the design decisions that must be made before launching a MOOC are identified in several works [30]. According to this study the design should be
Average length of the session

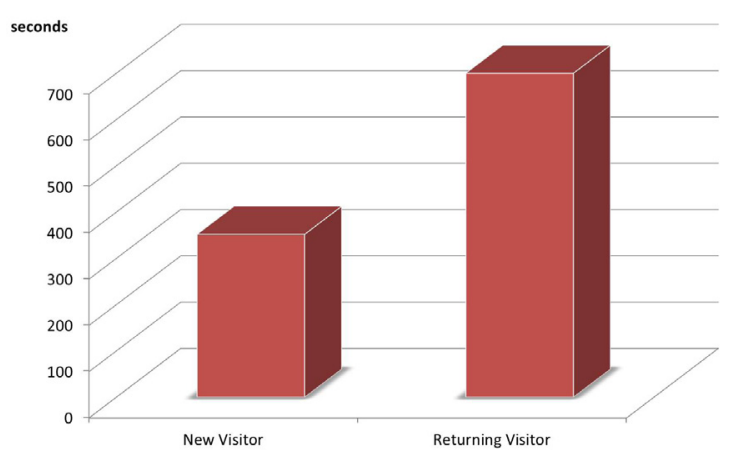

Figure 4. Average length of sessions, in seconds, according to type of visitors

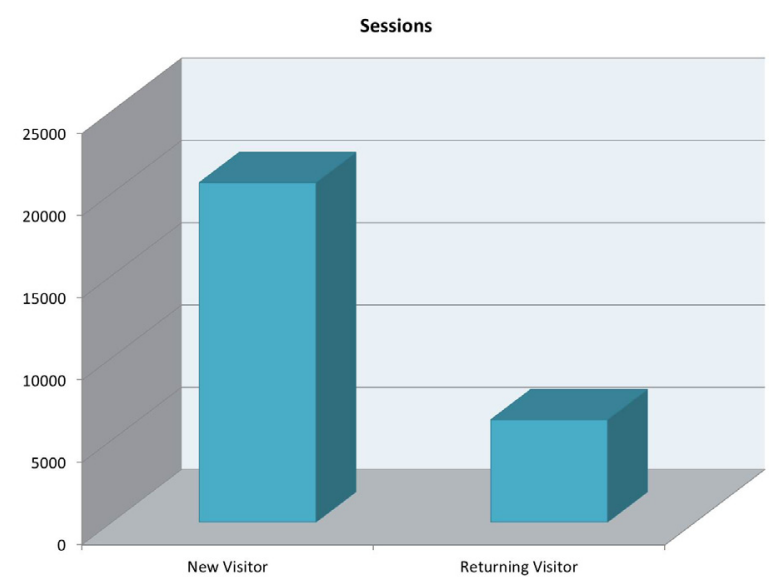

Figure 5. Distribution of sessions according to type of visitors

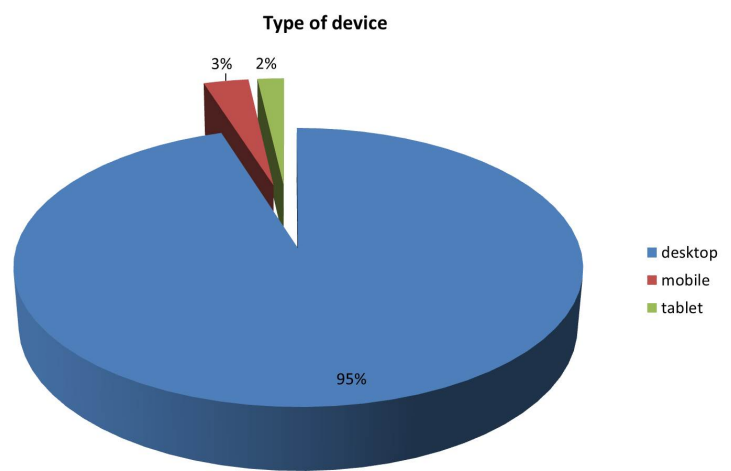

Figure 6. Type of electronic device used in their web browsing

agreed upon by the teaching staff and previous experiences of other teachers that have created MOOCs in the same area should be taken into account.

Many MOOC initiatives have recently emerged across the globe, such as Coursera, edX and Udacity in the United States, FutureLearn in the United Kingdom, iversity in Germany, FUN in France or MiríadaX in Spain.

\section{THE EDX PLATFORM}

The edX [31] learning platform is based on expanding the limits of knowledge and on being a showcase for students of any age, means and nationality, of an almost unlimited range of knowledge. As its own website states [31] "we take our mission of increasing global access to quality education seriously. We connect learners to the best universities and institutions from around the world". 
The edX concept is based on offering access "for anyone, anywhere". Five of the world's top 10 universities are edX members. Currently, edX offers more than 330 courses, which will be supplemented with another 200 courses hereafter; besides these, another 240 courses were archived. The learning platform offers a verified Certificate of Achievement, for almost 500 of these courses, which can be an incentive to enroll on it.

The edX publishes a wide offer of courses, whose distribution in areas can be found in Fig. 7. We can see that the most recurrent themes in the course are the courses on computer science, engineering, humanities, science and social sciences. A total of 1463 courses have been analyzed.

The edX courses should be adjusted to the rigorous standards prearranged by edX. In this case, they are summarized in Fig. 8.

Analyzing the total of courses offered in edX distributed by languages, it is clear that they are mostly in English, but the second most important language is Spanish. You can see the distribution of languages in Fig. 9.

\section{First Steps Of OUR EDX COURSE}

Once the results of the OCW-UPM Helicopters course were analyzed, and strongly supported by the Open Education Office of Universidad Politécnica de Madrid (Technical University of Madrid Open Education Office) the teachers' staff endorsed the main objectives of OEC (previously OCWC), after OEC was member edX; Technical University of Madrid is sustaining member of OCWC. The research questions were:

- How can reused OCW make MOOC development cost effective?

- How can reusing OCW increase collaboration opportunities? [32].

This challenge was possible because the Technical University of Madrid was invited to publish 2 courses in a pilot experience for new channel publishing edX courses, which take these objectives: OECx.

The course's proposal was in Spanish. The challenge of addressing the course for the teaching staff was so great, they considered that the first version of it was to be done in the teachers' mother tongue. All material evolved from their teaching experience, whose result was used in the prior OCW-UPM experience, could be a springboard to help tackle the task of structuring the information and materials in the original language. Once the results were clearly satisfactory, and with sufficient time to improve the difficulties encountered in the course's development, which will be mentioned in the article, the next challenge would be to offer the course in English.

As explained before, the course's validation standards are thorough and rigorous. Checklists were prepared to validate tasks that had to be verified on a calendar according to the starting and ending course dates. This MDC verification (MOOC Development Checklist) standardizes the quality of the course. The MDC verifies information concerning: course introduction, course syllabus, course structure and design, assessments, course videos, other instructional material, learner engagement and reruns, reusability and licensing.

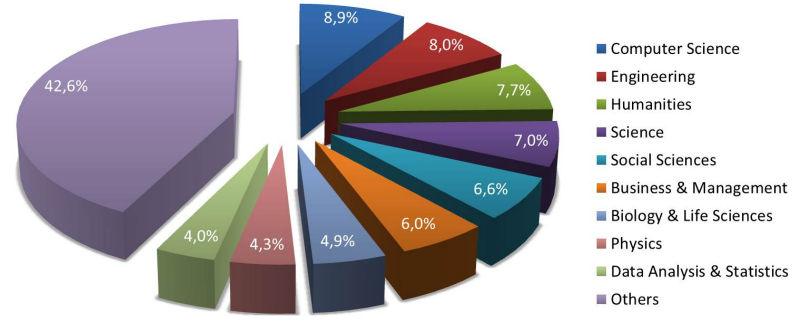

Figure 7. edX courses according to subjects

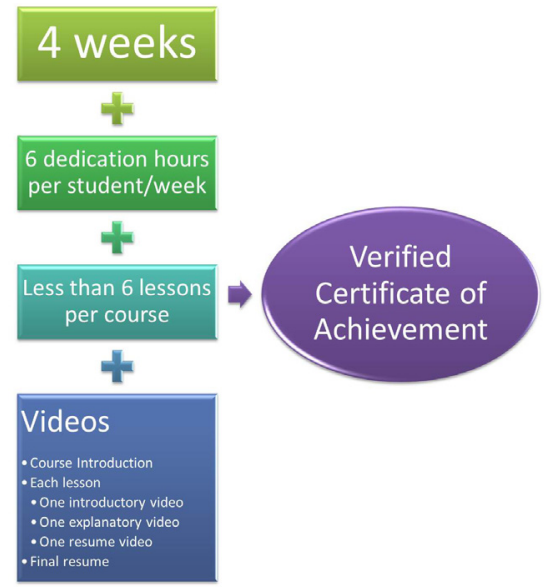

Figure 8. Main structure of edX courses

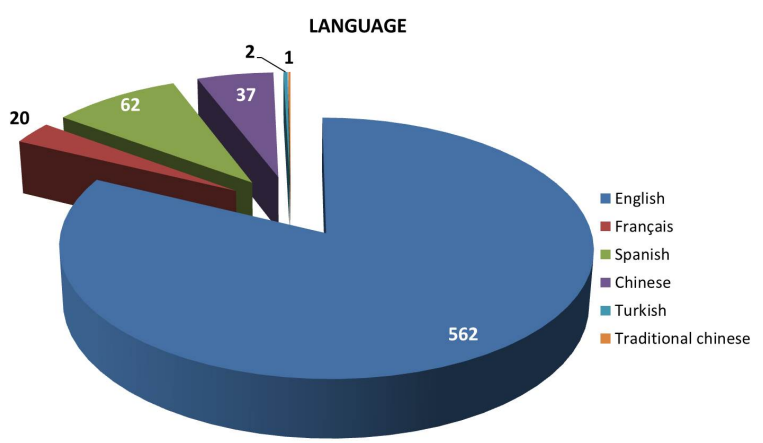

Figure 9. Languages in edX courses

The edX platform offers the teaching staff a tool that collects a set of statistical data on the participants and results of students' opinion [33].

\section{DATA ABOUT PARTICIPANTS}

It is interesting to see that there is a total of 98 countries represented, e.g., with at least one student participating in the course described in this article. Spain is the country with the largest number of participants, with $21 \%$ of the students. It is followed by Mexico with $11 \%$ of the students, and thirdly Colombia with a total of $10 \%$ of the students. Fig. 10 shows the data described above including the total value of the number of participants. It can be noticed that nearly 600 students who participated came from Spain.

Regarding the gender distribution, the result is clearly tilted towards the male gender. This distribution is consistent with the results shown in the access of new students to the Technical University of Madrid, where a concerning decline in women's vocations in engineering is happening. There is very interesting scientific literature on this aspect, with the analysis in its different aspects. It 
should be pointed out [34] and some possible suggestions for improvement. We noticed that men represent $79 \%$ versus $9 \%$ of women; about $12 \%$ of the students do not fill this information.

These values are comparatively lower than the figures published by MIT [35] showing a participation of around $30 \%$ of women in the different subjects they studied. This value is consistent with the amount of women students accessing to engineering and architecture studies at the Technical University of Madrid.

The next data that was relevant to the study for the teaching staff was the educational level of participants at the moment of access. This educational level determines if the course subject is interesting for a particular group in training, and, after analysing satisfaction surveys, if it met their expectations based on the previous level of demand. Fig. 11 shows the result of the analysis from before. More than $50 \%$ of the students entering the course are college students or graduates (bachelor, masters and doctorate). Although the approach of the course is at an introductory level, with prior requirements of basic knowledge of mathematics and physics, there is a challenge in adapting the materials for a heterogeneous participation group, but with a great interest in learning. We will compare these results with the students' participation in the final survey of the subject.

The percentage of students with a bachelor's level is below the one offered by [35] but similar if the level of studies includes bachelor and master's degrees, that is, nearly $60 \%$ compared to values close to $70 \%$ in courses offered by Harvard and MIT.

Once it seems clear that the MOOCs represent an essential and modern look in the LLL concept [28], the next step is to analyze the distribution of participants by age.

According to the main data of age metrics (of those students who provided a year of birth), we summarize that:

- The median student age was 27 , that is, the midpoint of the student ages, computed from the provided year of birth.

- The percentage of students aged 25 years or younger was $42.4 \%$.

- The percentage of students aged from 26 to 40 years was $44.1 \%$.

- The percentage of students aged 41 and over was $13.6 \%$.

Fig. 12 shows the distribution of the years of birth of the participants from which the above conclusions are drawn.

It is very interesting to note that this figure of the age distribution, where the median corresponds to 27 year olds, corresponds mimetically with the age distribution of edX courses offered by Harvard and MIT.

\section{COURSE Evolution}

The initial reception of the course was truly amazing. The first year it was offered (in spring 2015) the number of people enrolled reached over 2500 students. Of these, $1 \%$ asked for the certificate, for which they had to pay a 40 euro fee. This demand is lower than other courses offered by the edX platform, whose demand for certificates usually ranges close to $10 \%$. In that sense, it is noteworthy to study what [25] calls "zero moment of truth", that is,

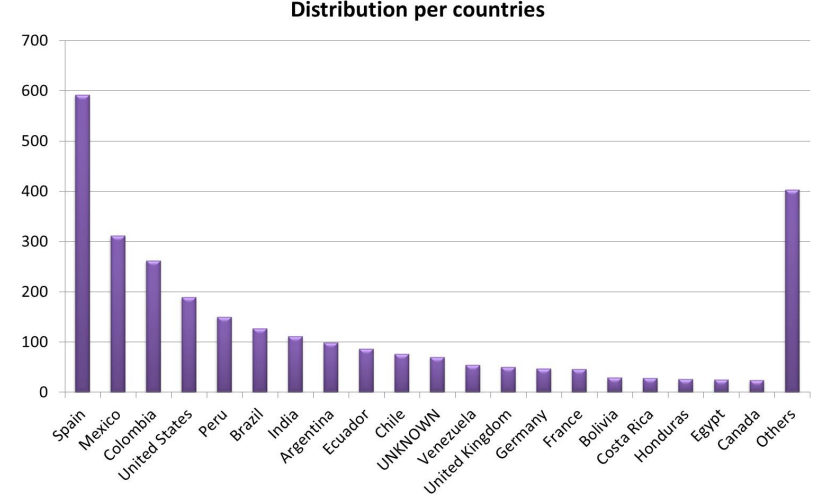

Figure 10. Distribution per countries according to participants' origin

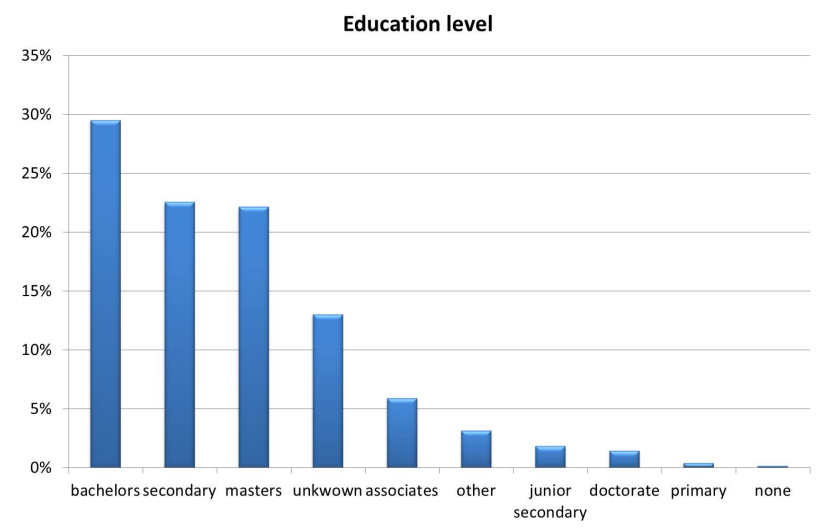

Figure 11. Students per education level

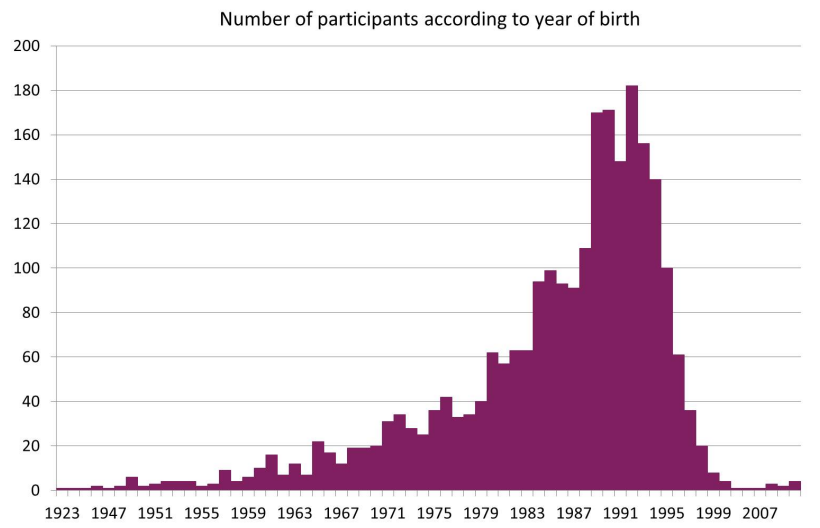

Figure 12. Year of birth of the participants

the decision-making moment at the time of registering for the courses.

In Fig. 13 we can observe the evolution through time of the enrollment in the course. The start date was April 13, 2015 and the date of completion May 8, 2015. The course allowed for a later registration after the date of completion, with the possibility to access the learning resources, but without the possibility of obtaining participation certificates.

It is interesting to study the evolution of the students' use of the learning tools. Conclusions can be drawn about the adequacy of these tools from their continued use.

In Fig. 14 we can check the progress of the application for the verified certificate of participation. It can be noted that obviously the maximum point coincides with the start date of the course. A decrease in enrollment can also be observed since the platform allows cancelling the request. 


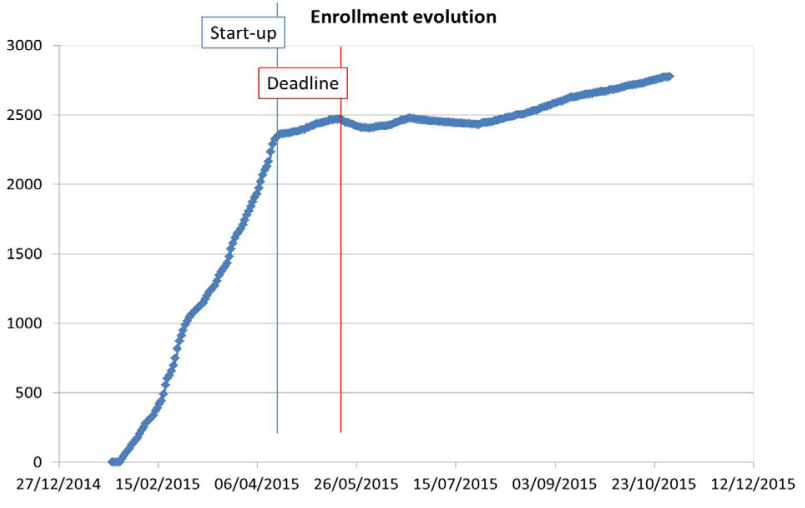

Figure 13. Enrollment evolution

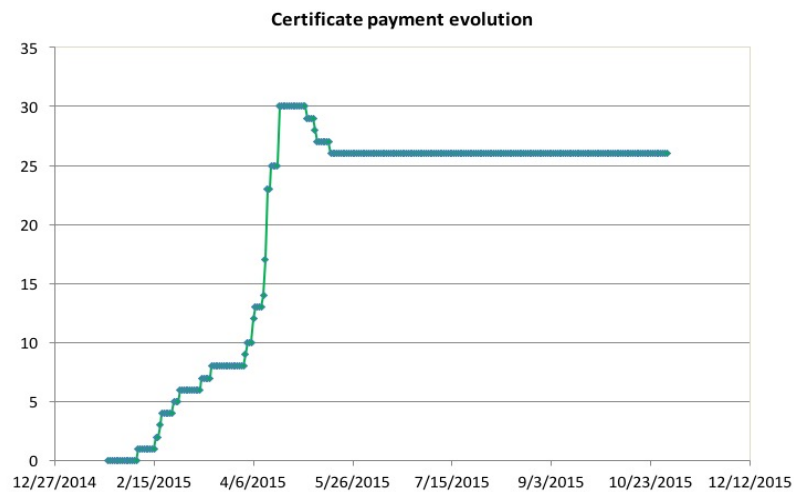

Figure 14. Daily evolution of the course certificate payment

It is interesting to study the evolution of the students' use of the learning tools. We show it on Fig. 15. Conclusions can be drawn about the adequacy of these tools from their continued use.

In light of these results, a decrease can be analyzed in the students' activity after the initial registration. This decrease is usual in any such course, but in any case the teaching staff will consider this information for future course versions, in order to keep the attention and interest of the students during the four weeks.

Students could show their personal point of view in each of the weeks of the course. It should be kept in mind that the thematic blocks must be adjusted by weeks, with practical exercises and self-assessment tests. This information is included in Fig. 16. Interestingly, the students' point of view shows that the second week has the worst results, but finally the last week stands out positively.

\section{Analysis Of The Final Surveys}

From the survey [36] results we can draw conclusions for improvement. The number of students who voluntarily participated in the final polls was significantly lower than the total of participants.

It is very interesting to study the employment status of the participating students. Such information is available, but only about those students who completed the final survey. It can be considered a representative sample of the total of the course's participants. It is observed that $63 \%$ of students are employed (full or part time). We can analyze this employment status in Fig. 17. The authors consider that it is a positive aspect related with LLL concept. Many students keep in contact with university after they finish their studies, and they want to improve their knowledge and skills.

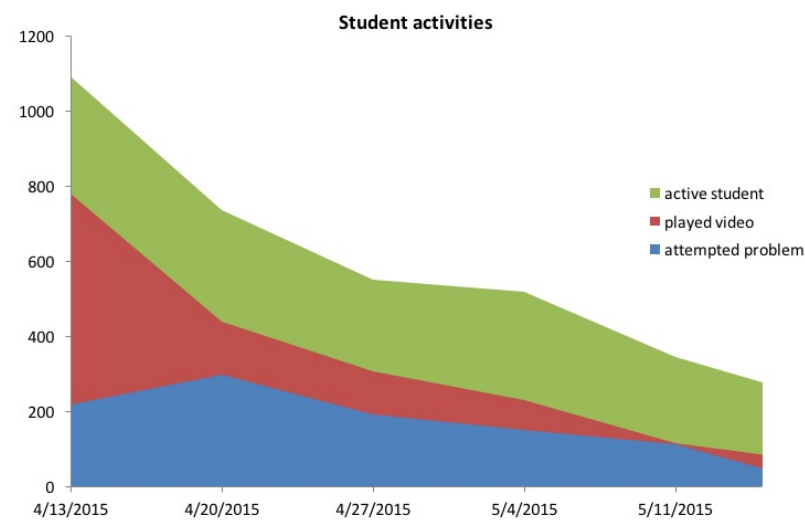

Figure 15. Student activities during the course

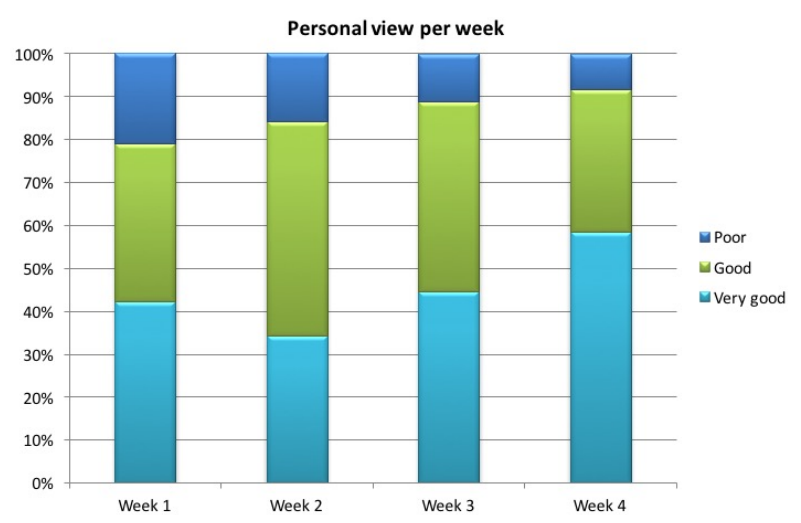

Figure 16. Evolution during the course of the students' personal view. Per week

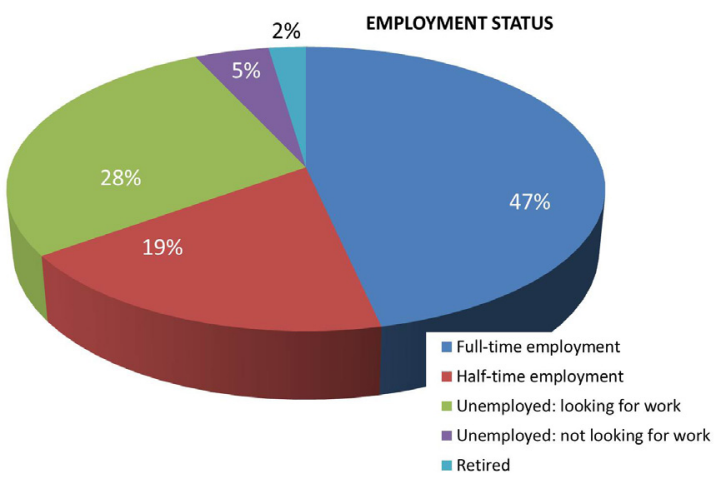

Figure 17. Employment status of the students

It is essential to know the importance of the learning resources for the students. The teaching resources will be used throughout the course, but also will be very important for the student to be valid after the course. If your opinion is very favorable for future use, the focus of the materials is correct. Of the students surveyed, over $75 \%$ believe that they will use the resources in the future. The teachers think that this is a very encouraging result.

$62 \%$ of the students also highlighted that the learning system was correct. $60 \%$ of the students evaluated positively the response speed of the platform. Still, the teaching team considers that this aspect can be clearly improved, but consider it normal for the novelty of the course.

However we are aware that some aspects of the course should be improved. We believe that our demand to improve the results relating to the expectations of the participants must be taken into account. 


\section{CONCLUSIONS}

The paper has presented the work done by the teaching team in two courses focused on blended learning. In both cases, these are courses for the degree in aerospace engineering and the subject was Helicopters. The first experience was developed in the OCW-UPM, and the second one was published in edX platform. The major aspects of the open MOOC courses within edX have been presented.

The result of the participation was strongly positive. These two platforms allow the authors to obtain a lot of information during the course to establish conclusions. In the edX course there were final satisfaction surveys that have enabled to draw some interesting decisions for future versions of the course. Teaching staff satisfaction is very high, but should correct some deficiencies that have been explained throughout this work.

\section{ACKNOWLEDGMENTS}

The teaching staff would like to thank the technical and logistical support received from the UPM Open Education Office and E-Education Office (GATE) for developing the course's structure.

\section{REFERENCES}

[1] Hannafin, M., Land, S., \& Oliver, K. (1999). Open learning environments: Foundations, methods, and models. Instructional-design theories and models: A new paradigm of instructional theory, 2, 115-140.

[2] Barcala-Montejano, M.A. Rodríguez-Sevillano, A. A. The Experience of Helicopters subject- course in the OCW-UPM Project. A Proposal on Technology Dissemination. 2011 IEEE Global Engineering Education Conference (EDUCON). Amman 4-6 April 2011. Pag 236-241. http://dx.doi.org/10.1109/EDUCON.2011. $\underline{5773143}$

[3] Piedra, N., Chicaiza, J., Lopez, J., \& Tovar Caro, E. (2014, April). Supporting openness of MOOCs contents through of an OER and OCW framework based on Linked Data technologies. In Global Engineering Education Conference (EDUCON), 2014 IEEE (pp. 1112-1117). IEEE. http://dx.doi.org/10.1109/educon.2014.682 $\underline{6249}$

[4] Gao, J., Qu, J., \& Xin, Z. (2015). Towards on the MOOCs Knowledge Discovery Based on Concept Lattice. International Journal of Multimedia and Ubiquitous Engineering, 10(5), 287296. http://dx.doi.org/10.14257/ijmue.2015.10.5.26

[5] Van Dijck, J., \& Poell, T. (2015). Higher Education in a Networked World: European Responses to US MOOCs. International Journal of Communication, 9, 19.

[6] Delgado Kloos, C., Munoz-Merino, P. J., Alario-Hoyos, C., Estevez Ayres, I., \& Fernandez-Panadero, C. (2015, March). Mixing and blending MOOC Technologies with face-to-face pedagogies. In Global Engineering Education Conference (EDUCON), 2015 IEEE (pp. 967-971). IEEE. http://dx.doi.org/10.1109/EDUCON. $\underline{2015.7096090}$

[7] Sammour, G., Al-Zoubi, A., Gladun, A., Khala, K., \& Schreurs, J. (2015, December). MOOCs in universities: Intelligent model for delivering online learning content. In 2015 IEEE Seventh International Conference on Intelligent Computing and Information Systems (ICICIS) (pp. 167-171). IEEE. http://dx.doi.org/10.1109/Intel CIS.2015.7397216

[8] Daradoumis, T., Bassi, R., Xhafa, F., \& Caballé, S. (2013, October). A review on massive e-learning (MOOC) design, delivery and assessment. In P2P, Parallel, Grid, Cloud and Internet Computing (3PGCIC), 2013 Eighth International Conference on (pp. 208213). IEEE.

[9] Yousef, A. M. F., Chatti, M. A., Schroeder, U., \& Wosnitza, M. (2014, July). What Drives a Successful MOOC? An Empirical Examination of Criteria to Assure Design Quality of MOOCs. In Advanced Learning Technologies (ICALT), 2014 IEEE 14th International Conference on (pp. 44-48). IEEE. http://dx.doi.org/10.1109/ icalt.2014.23
[10] Khalil, M., \& Ebner, M. (2015, September). A STEM MOOC for school children-What does learning analytics tell us?. In Interactive Collaborative Learning (ICL), 2015 International Conference on (pp. 1217-1221). IEEE.

[11] Salzmann, C., Gillet, D., \& Piguet, Y. (2016, February). MOOLs for MOOCs: A first edX scalable implementation. In 2016 13th International Conference on Remote Engineering and Virtual Instrumentation (REV) (pp. 246-251). IEEE. http://dx.doi.org/10.1109/rev.2016.7444473

[12] Huba, M., Rovanova, L., \& Marko, L. (2013, October). From automatic feedback systems to MOOCs. In Emerging eLearning Technologies and Applications (ICETA), 2013 IEEE 11th International Conference on (pp. 151-158). IEEE. http://dx.doi.org/10.1109/iceta.2013.6674421

[13] Lei, C. U., Hou, X., Kwok, T. T., Chan, T. S., Lee, J., Oh, E., ... \& Lai, C. (2015, December). Advancing MOOC and SPOC development via a learner decision journey analytic framework. In Teaching, Assessment, and Learning for Engineering (TALE), 2015 IEEE International Conference on (pp. 149-156). IEEE. http://dx.doi.org/10.1109/tale.2015.7386034

[14] Martin, S., Castro, M., Gago, D., \& Torres, D. (2013, August). Empowering communities on line: A Massive Open Online Community on App Development and Entrepreneurship. In Teaching, Assessment and Learning for Engineering (TALE), 2013 IEEE International Conference on (pp. 37-40). IEEE. http://dx.doi.org/10.1109/tale.2013.6654395

[15] Alzaghoul, A., \& Tovar, E. (2016, February). A proposed framework for an adaptive learning of Massive Open Online Courses (MOOCs). In 2016 13th International Conference on Remote Engineering and Virtual Instrumentation (REV) (pp. 127-132). IEEE.

[16] http://www.oeconsortium.org/

[17] http://www.oeconsortium.org/2015/07/open-moocs-offeredthrough-the-oecx-partnership-expand/

[18] Ferschke, O., Yang, D., Tomar, G., \& Rosé, C. P. (2015, June). Positive Impact of Collaborative Chat Participation in an edX MOOC. In Artificial Intelligence in Education (pp. 115-124). Springer International Publishing. http://dx.doi.org/10.1007/978-3319-19773-9 12

[19] Boneu, J. M. (2007). Plataformas abiertas de e-learning para el soporte de contenidos educativos abiertos. RUSC. Universities and Knowledge Society Journal, 4(1), 8.

[20] Alonso, F., López, G., Manrique, D., \& Viñes, J. M. (2005). An instructional model for web-based e-learning education with a blended learning process approach. British Journal of educational technology, 36(2), 217-235. http://dx.doi.org/10.1111/j.14678535.2005.00454.x

[21] Almenara, J. C. (2006). Bases pedagógicas del e-learning. DIM: Didáctica, Innovación y Multimedia, (6). (spanish)

[22] Vahdati, S., Lange, C., \& Auer, S. (2015, March). OpenCourseWare observatory: does the quality of OpenCourseWare live up to its promise?. In Proceedings of the Fifth International Conference on Learning Analytics And Knowledge (pp. 73-82). ACM. http://dx.doi.org/10.1145/2723576.2723605

[23] Tovar, E., \& Piedra, N. (2014). Guest Editorial: Open Educational Resources in Engineering Education: Various Perspectives Opening the Education of Engineers. Education, IEEE Transactions on, 57(4), 213-219. http://dx.doi.org/10.1109/TE.2014.2359257

[24] Martinez-Bonastre, O., Tovar, E., \& Castro, M. (2016, February). Open educational resources and competences related with practices and laboratories. In 2016 13th International Conference on Remote Engineering and Virtual Instrumentation (REV) (pp. 1-2). IEEE.

[25] Martín, A. G., González, A. T., \& Ruiz, J. D. (2015). Oferta de MOOC en España. Zero Moment of Truth (ZMOT). RELATEC: Revista Latinoamericana de Tecnología Educativa, 14(2), 11-23. (spanish)

[26] Castro, M., Tawfik, M., \& Tovar, E. (2015). Digital and Global View of Engineering Education Using Remote Practical Competences. Tecnologias del Aprendizaje, IEEE Revista Iberoamericana de, 10(3), 126-133. http://dx.doi.org/10.1109/RITA.2015. 2452651

[27] González-González, C. S. (2012). Sección Especial Campus Virtuales. IEEE-RITA, 7(4), 211-212. 
[28] Steffens, K. (2015), Competences, Learning Theories and MOOCs: Recent Developments in Lifelong Learning. European Journal of Education, 50: 41-59. http://dx.doi.org/10.1111/ ejed. 12102

[29] Timothy Read, Covadonga Rodrigo, Toward a Quality Model for UNED MOOCs, eLearning Papers, ISSN: 1887-1542, www.openeducationeuropa.eu/en/elearning_papers n. ${ }^{0} 37$, March 2014.

[30] Carlos Alario-Hoyos, Mar Pérez-Sanagustín, Carlos DelgadoKloos, Israel Gutiérrez-Rojas, Derick Leony, Hugo A. Parada G, Designing Your First MOOC from Scratch: Recommendations After Teaching "Digital Education of the Future", eLearning Papers • ISSN: 1887-1542, www.openeducationeuropa.eu/en/elearning papers n. ${ }^{\circ} 37 \cdot$ March 2014.

[31] https://www.edx.org/

[32] Tovar, E., Dimovska, A., Piedra, N., \& Chicaiza, J. (2013, March). OCW-S: Enablers for building sustainable open education evolving OCW and MOOC. In Global Engineering Education Conference (EDUCON), 2013 IEEE (pp. 1262-1271). IEEE. http://dx.doi.org/10.1109/educon.2013.6530269

[33] Freire, M., del Blanco, Á., \& Fernández-Manjón, B. (2014, April). Serious games as edX MOOC activities. In Global Engineering Education Conference (EDUCON), 2014 IEEE (pp. 867-871). IEEE. http://dx.doi.org/10.1109/educon.2014.6826198

[34] Brainard, S. G., \& Carlin, L. (1997, November). A longitudinal study of undergraduate women in engineering and science. In Frontiers in Education Conference, 1997. 27th Annual Conference. Teaching and Learning in an Era of Change. Proceedings. (Vol. 1, pp. 134-143). IEEE.

[35] Ho, A. D., Chuang, I., Reich, J., Coleman, C., Whitehill, J., Northcutt, C., ... \& Petersen, R. (2015). HarvardX and MITx: Two years of open online courses.
[36] Rodríguez-Sevillano, A. A., Barcala-Montejano, M. A., \& TovarCaro, E., López-Gallego, P. (2016, February). Evolution of teaching tools and the learning process: From traditional teaching to edX courses. In 2016 13th International Conference on Remote Engineering and Virtual Instrumentation (REV) (pp. 48-55). IEEE.

\section{AUTHORS}

Dr. A.A. Rodríguez is professor of aerospace engineering at the School of Aeronautics and Space Engineering. Plaza del Cardenal Cisneros, 3. 28040 Madrid. Spain. (angel.rodriguez.sevillano@upm.es)

Dr. M.A. Barcala is professor of aerospace engineering at the School of Aeronautics and Space Engineering. He is the head of Department of Aircraft and Space Vehicles. Plaza del Cardenal Cisneros, 3. 28040 Madrid. Spain. (miguel.barcala@upm.es)

Dr. E. Tovar is professor of computer engineering at the School of Computer Engineering. He is member of the Board of Governors of the IEEE Education Society. Campus de Montegancedo. 28660 Madrid. Spain. (edmundo.tovar@upm.es)

P. López is student of computer engineering at the School of Computer Engineering, Universidad Politécnica de Madrid, Campus de Montegancedo, 28660 Madrid, Spain.

Submitted, 30 May 2016. Published as resubmitted by the authors on 09 June 2016. 